\title{
Coastal sand dune ecosystem services in metropolitan suburbs: effects on the sake brewery environment induced by changing social conditions
}

\author{
Korehisa Kaneko ${ }^{1 *}$ and Hajime Matsushima ${ }^{2}$
}

\begin{abstract}
Chiba Prefecture, Japan, lies very near Tokyo, the capital city of Japan. It borders the sea on three sides and is banded by coastal dunes. Several sake breweries are located near these dunes. Although there are records of sake brewing along the coast of Tokyo Bay since 1925, sake breweries have completely disappeared in several areas. We believe that sake brewing in these areas benefited from the ecosystem services afforded them by their proximity to the coastal ecosystem. We investigated potential environmental factors (e.g., landscape, soil, and groundwater), as well as conditions that could have driven sake brewers away from the coastal area. Many of the sake breweries that no longer exist were located on coastal dunes (i.e., sand, sandbanks, and natural levees) and obtained their water from a freshwater layer located 3-10 m below the surface. We speculate that these sake breweries benefited from using natural ingredients found in the coastal zone. We also investigated the following factors that may have negatively impacted the breweries, driving them out of business: (1) bankruptcies and reconstruction difficulties that followed the destructive 1923 Great Kanto earthquake, (2) industrial wartime adjustments during World War II (1939-1945), (3) development of coastal industries during the period from 1960 to 1975, and (4) increasing choices for other alcoholic drinks (e.g., beer, wine, and whiskey) from the 1960s to the present.
\end{abstract}

Keywords: Ecosystem service, Coastal dune system, Land use change, Japanese sake, Brewing, Soil and groundwater

\section{Introduction}

Japanese sake is brewed from rice and water, which are the central ingredients of the food culture of Japan. Sake is produced by a singular fermentation technology that applies the power of microorganisms. The beverage has attracted attention worldwide. In addition, sake is an alcoholic drink specific to Japan and a component of a traditional food culture that has continued for approximately 2000 years (Food and Beverage Specialist Organization NPO 2009). Japan's traditional food culture, known as "Washoku," was given UNESCO intangible cultural heritage status on December 4, 2013. The sake industry, however, is in decline. There were over 4000 licensed sake breweries in 1955, but their number

\footnotetext{
* Correspondence: k_kaneko@hotmail.com

'Hokuso Creature Association, 4-20-5 Tabata, Kita-Ward, Tokyo 114-0014, Japan

Full list of author information is available at the end of the article
}

had dropped to about 1600 in 2016, and consumption of sake has decreased, as of 2015, by two thirds since 1974 (National Tax Agency HP: http://www.nta.go.jp/kohyo/ tokei/kokuzeicho/jikeiretsu/01.htm).

The diverse natural environment in which sake is brewed includes coastal sand dunes, river plains, hills, and mountains. The natural characteristics of these environments (e.g., soil, groundwater quality, and climate) substantially affect the taste of the finished product. Water has a significant impact on the taste of sake. In sake brewed in coastal dune systems, the freshwater layer that lies $5-10 \mathrm{~m}$ below the ground surface provides mineral-rich, hard water in that is high in calcium and magnesium. These nutrients actively promote the proliferation of Aspergillus oryzae and yeast, the predominant microorganisms used in sake brewing. The taste of Japanese sake from such coastal areas is dry and full-bodied (Kaneko et al. 2012, 2013). 
As detailed by the records of Chiba Prefecture, Japan, the number of sake breweries in the coastal areas around Tokyo Bay during Japan's Taisho era (1912-1926) was 5-10 times higher than at present (Suzuki 1997). A freshwater layer forms under coastal sand dunes, and it is this water that is used in sake brewing. Chiba Prefecture's Tokyo Bayside, near the Japanese capitol, is formed on coastal sand dunes. This area flourished in ship transportation in the Edo era (1603-1868), and there were many sake breweries there. The sake brewing conducted there used the water from the freshwater layer in its brewing processes, making use of an ecosystem service. The term "ecosystem service" means the benefits that human beings receive from the bounty of nature. Sake breweries have been supporting this region for a few hundred years, and brewing has received the natural benefits of the coastal sand dunes (terrain, soil, water quality, etc.). However, because these areas faced Tokyo, there has been extensive infrastructure maintenance and coastal development since the high economic growth period of the 1960s. The coastal sand dunes of Tokyo Bayside have been affected by urban development, and most of the sake breweries have closed.

In this study, we investigate sake brewing in these areas, which benefitted from the natural environment, and factors that have led to its decline, based on a survey of the social changes such as land development that have occurred in the coastal area, modifying those features that promoted sake brewery during the Taisho era (1912-1926).

\section{Methods/Experimental Study site}

Chiba Prefecture is located east of Tokyo and is bordered on three sides by the sea (Fig. 1). In several parts of Chiba, there is a band-shaped coastal dune system (Fig. 2). The number of sake breweries concentrated in the coastal regions known as Uchibo (inner) and Sotobo (outer) has dropped substantially in the last century. Figure 3 shows the number of sake breweries by municipality in 1925 and the locations of breweries operating in 2012, grouped topographically.

Although there is only one sake brewery currently operating in the coastal area of Tokyo Bay, records show that in 1925, there were sake breweries in many parts of what is now Chiba City, including Makuhari Town (present-day Hanamigawa Ward), Kemigawa Town (Inage Ward), and Shiina Village (Midori Ward). In addition, there were breweries in Goi Town (present-day Ichihara City), Kaneda Village and Kisarazu Town (present-day Kisarazu City), and Funagata Town, Nako Town, Hojo Town, and Tateyama Town (present-day Tateyama City) (Fig. 4).

\section{Locations and soil and groundwater environments of sake breweries}

For information regarding historical and current sake breweries, we relied on Suzuki (1997) and Kaneko et al. (2012, 2013). In our research, we investigated the environment, including soil, topography, groundwater, and land use around sake breweries recorded in 1925. We investigated the soil and topography using subsurface geological maps, topographic maps, and soil maps created based on borings and well surveys (Ministry of Land, Infrastructure, Transport and Tourism, National Land Information). Groundwater conditions are described using groundwater quality data collected by Chiba Prefecture. Groundwater sampling and analysis were conducted in 1953,1963, 1965, and 1966, during the development of coastal area in Chiba Prefecture. Since that time, very little further development has occurred in that area. We assumed that the study sites enjoyed a natural coastal environment in the 1950s and 1960s. Groundwater hardness was based on the American scale (soft 0-60 ppm, medium hard 60-120 ppm, hard 120-180 ppm, very hard 180 ppm or more), which is the reference standard of the World Health Organization (2011). The land use investigation used blank maps for 1925, 1930, 2004, and 2009 from the Geospatial Information Authority of Japan. To investigate extinction factors for sake brewing, we conducted an oral survey with individuals who were engaged in local sake brewing in 1925.

We calculated sake production rates in Chiba Prefecture as an indicator of how many people in Chiba Prefecture are economically dependent on sake, based on the volume of sake produced in Chiba Prefecture and sake imported from other prefectures:

$$
Y=A /(A+B)
$$

where $Y$ is the sake production rate, $A$ is the volume produced in Chiba Prefecture, and $B$ is the volume transferred from outside the prefecture.

\section{Results and discussion}

Change in the number of sake breweries in Chiba Prefecture In the 1880s, there were more than 1100 sake breweries in Chiba Prefecture. However, according to an official announcement that prohibited home-brewed sake in 1899, this number decreased to 383 by 1896 . Later, many brewing companies suspended operations because of the Industrial Adjustment Act issued during World War II (1939-1945), and the number of sake breweries had decreased to 68 in 1946. During the high economic growth period of the 1960s and afterward, the number of sake breweries continued to decrease, reaching 39 in 2012 (Fig. 5). 


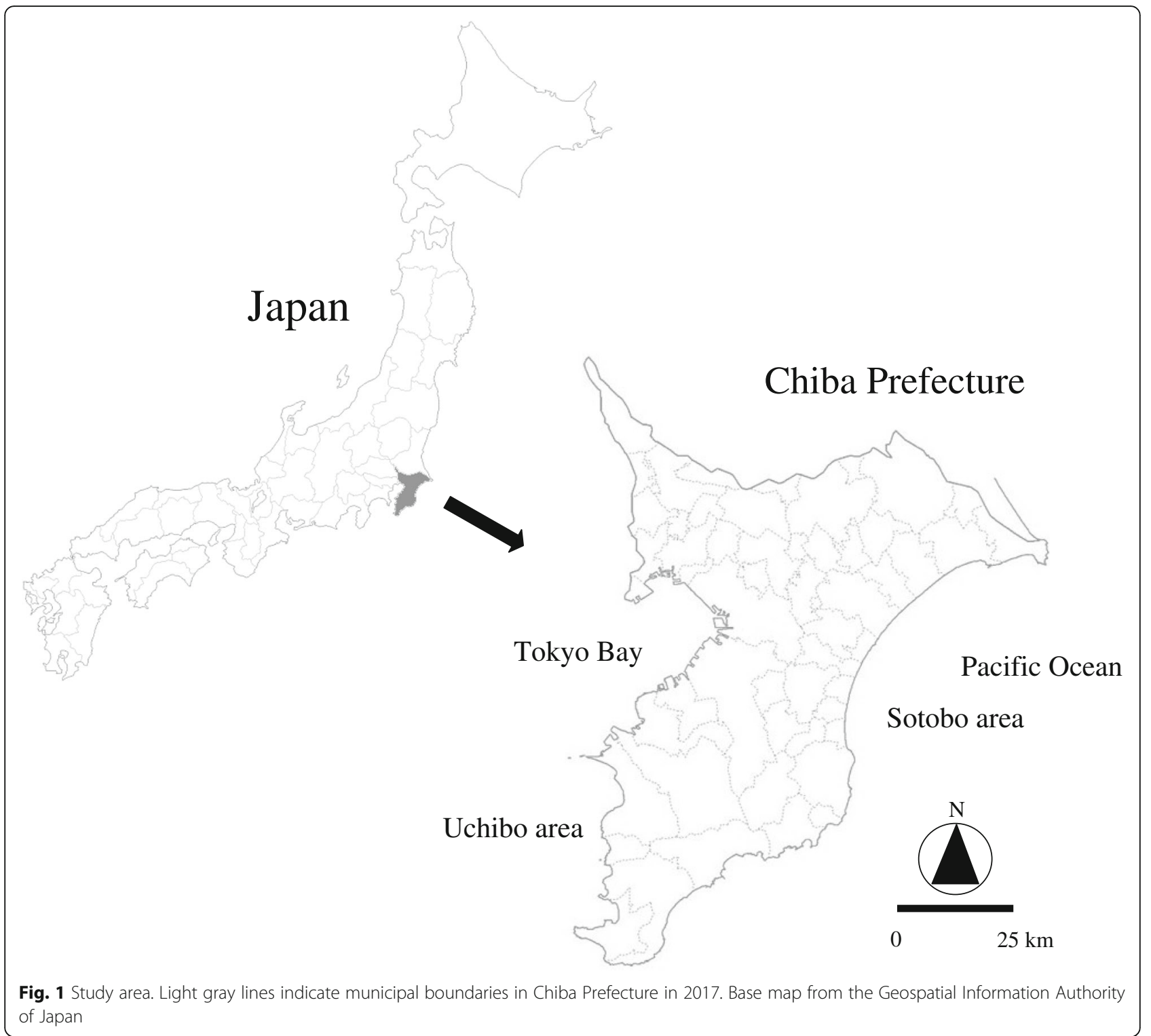

As Fig. 5 shows, there were 168 sake breweries in Chiba Prefecture in 1925 (Chiba Prefecture Brewing Association 1925), four times the number that existed in 2012.

In 1925, there were 56 sake breweries in the coastal vicinity. In 2012, there were 10 . The number of sake breweries along the coast has thus decreased to one fifth of the 1925 number (Fig. 6).

\section{Land use change}

We investigated land use changes by comparing base maps created by the Geospatial Information Authority of Japan. Land use changes in the coastal dune system have been remarkable in MakuhariTown, Kemigawa Town, Shiina Village, Goi Town, Hojo Town, and Tateyama Town (Fig. 7). In 1925 (Fig. 7a; left), Makuhari Town was a fishing village with a foreshore tidal flat spread in front of the town. By 2009 (Fig. 7a; right), this 5-6 km tidal flat had been substantially changed by development of residential and industrial areas. In 1920 (Fig. 7b; left), Kemigawa Town had a foreshore tidal flat that spread $3 \mathrm{~km}$ toward the sea. By 2009 (Fig. 7b; right), this area had been transformed into a coastal industrial zone. In 1920 (Fig. 7c; left), Shiina Village was an agricultural village on sand approximately $2 \mathrm{~km}$ inland from the sea. A sake brewery was located on the sand, and the expansive coastal area around the sake brewery included rice paddies. However, by 2004 (Fig. 7c; right), the $3 \mathrm{~km}$ foreshore seaward tidal flat had been developed into an industrial zone. In 1925 (Fig. 7d; left), Goi Town was a fishing and agricultural town with a predominantly natural coastline. The expanse of sand and wetlands that existed in 1925 was developed into a coastal industrial zone by 


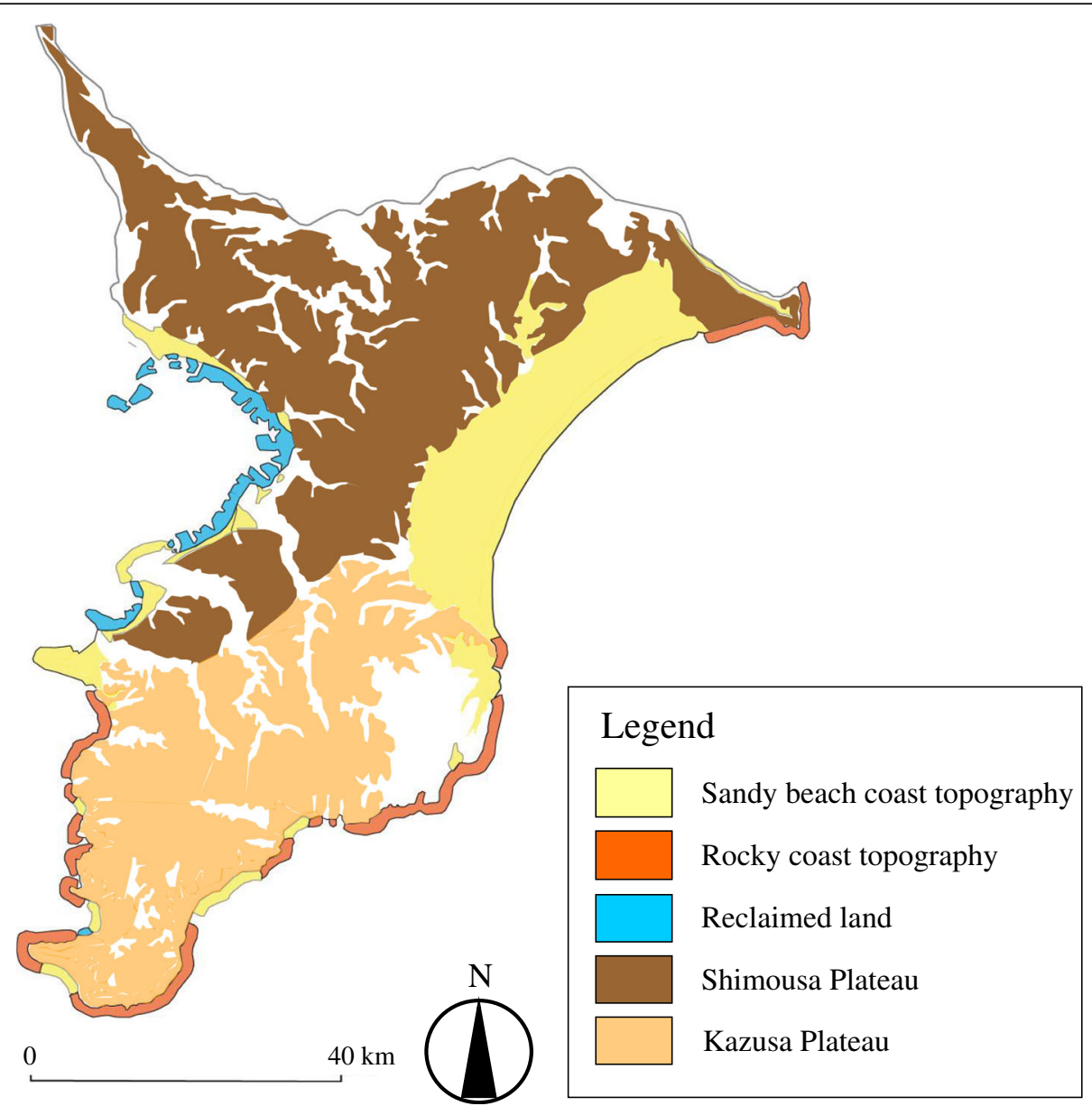

Fig. 2 Distribution of coastal topography in Chiba prefecture, Japan (Chiba Prefecture 2001)

2004 (Fig. 7d; right). Hojo and Tateyama Towns were fishing and sightseeing towns on a predominantly natural sandy coastline. Although these towns were near the coast in 1930 (Fig. 7e; left), by 2004 (Fig. 7e; right), the town area had expanded because of residential-area growth and the construction of the Ground SelfDefense Force's Tateyama Airport. The character of what were the central parts of these towns in 1925 has changed substantially because of the progressive development of residential areas, roads, and industrial land. Notably, the sake breweries operating in 1925 were located along what was then the main street.

\section{Soil and topography}

The surface geology consists of sand-rich sediments (in which the sand and sandbanks in the coastal region consist of fine-to-medium grain sand) and sand 1, which is a stratum of fine-to-medium grain and coarse sand sandwiching a layer of gravel and clay. Mud-rich sediments are distributed along the tributaries that traverse the valley lowlands of the river, plateaus, and coastal lowlands that face Tokyo Bay in a stratum approximately $10-20 \mathrm{~m}$ thick.
The coastal area of the study site is primarily occupied by sand-rich sediments. Its land classification is dominated by sandbanks, natural levees, sand bars, and covering dunes (i.e., a sandbar-sandbank beach ridge that consists of sand formed by waves and coastal currents in the coastal vicinity) (Table 1). According to a survey-based soil and land classification of Makuhari Town from the sea to the terrestrial area, its land is classified as sandbanks, natural levees, a valley plain, and middle gravel terraces in the terrestrial area (Fig. 8a; left). The surface geology moving inland is sand-rich sediment, loam formations, mud-rich sediment, sand, and then loam formations, with the strata formed by the weathering of volcanic ash deposits in the terrestrial area (Fig. 8a; right). In Kemigawa Town, Shiina Village, and Goi Town, the land is classified as having alternating repeated sandbanks, natural levees, valley plains, coastal plains, and delta plains, with middle gravel terraces in the terrestrial area (Fig. 8b-d; left). The surface geology has alternately repeating mud-rich sediment and a stratum of sand 1 approximately $10-20 \mathrm{~m}$ thick, with loam formations in the terrestrial area (Fig. 8b-d; right). In Tateyama Town, the 


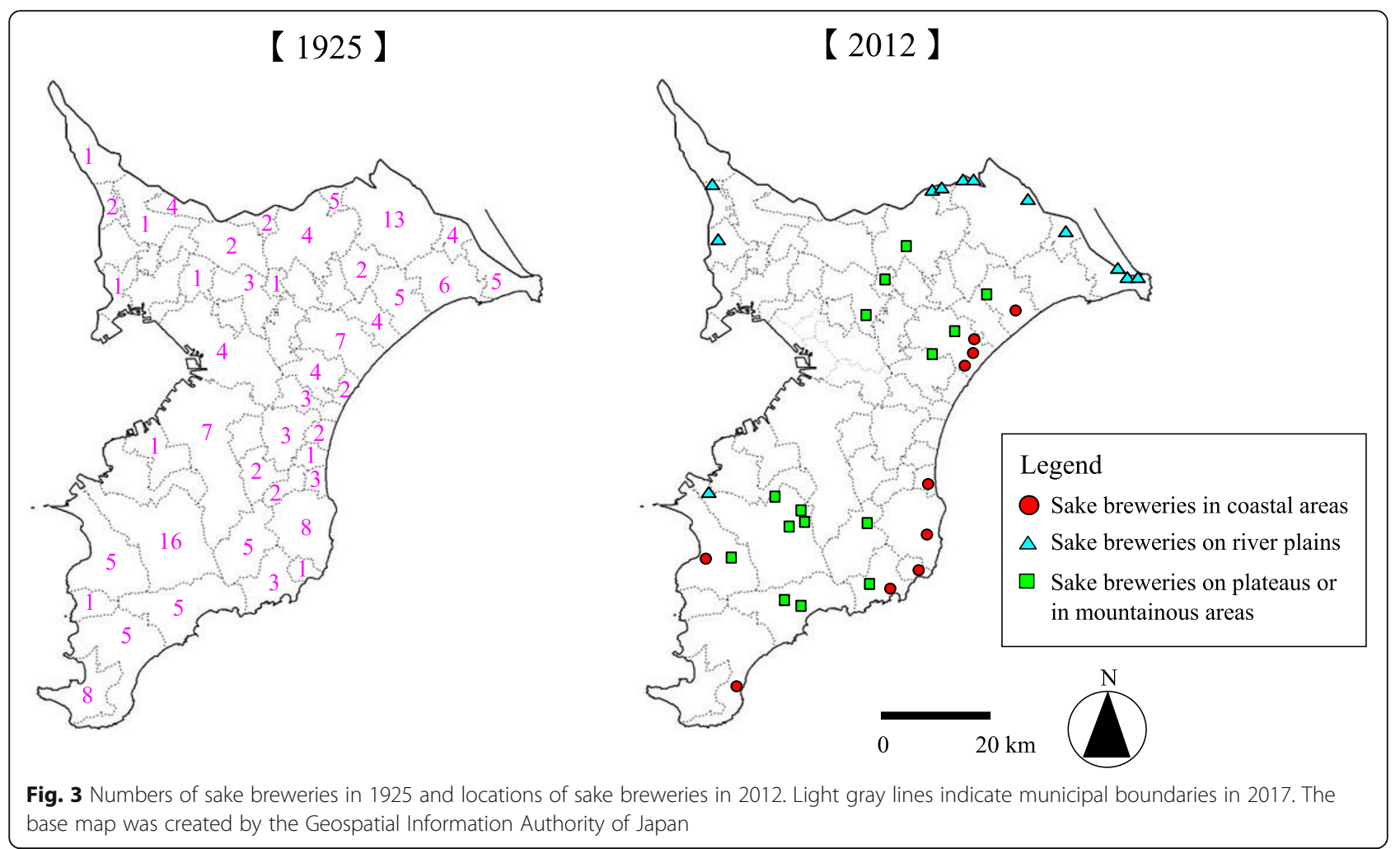

land is classified as alternately repeated sandbars, inter-bar lowlands, and naked dunes and includes river terraces and dissected hills in the terrestrial area (Fig. 8e; left). The surface geology shows alternately repeated mud-rich and sand-rich sediments and with sandstone and mudstone in the terrestrial area (Fig. 8e; right). The postulated natural environment had alternately repeating sand and wetlands from the sea to the terrestrial area and included middle gravel terraces, coastal terraces, or dissected hills. We investigated the soil environment of each sake brewery that

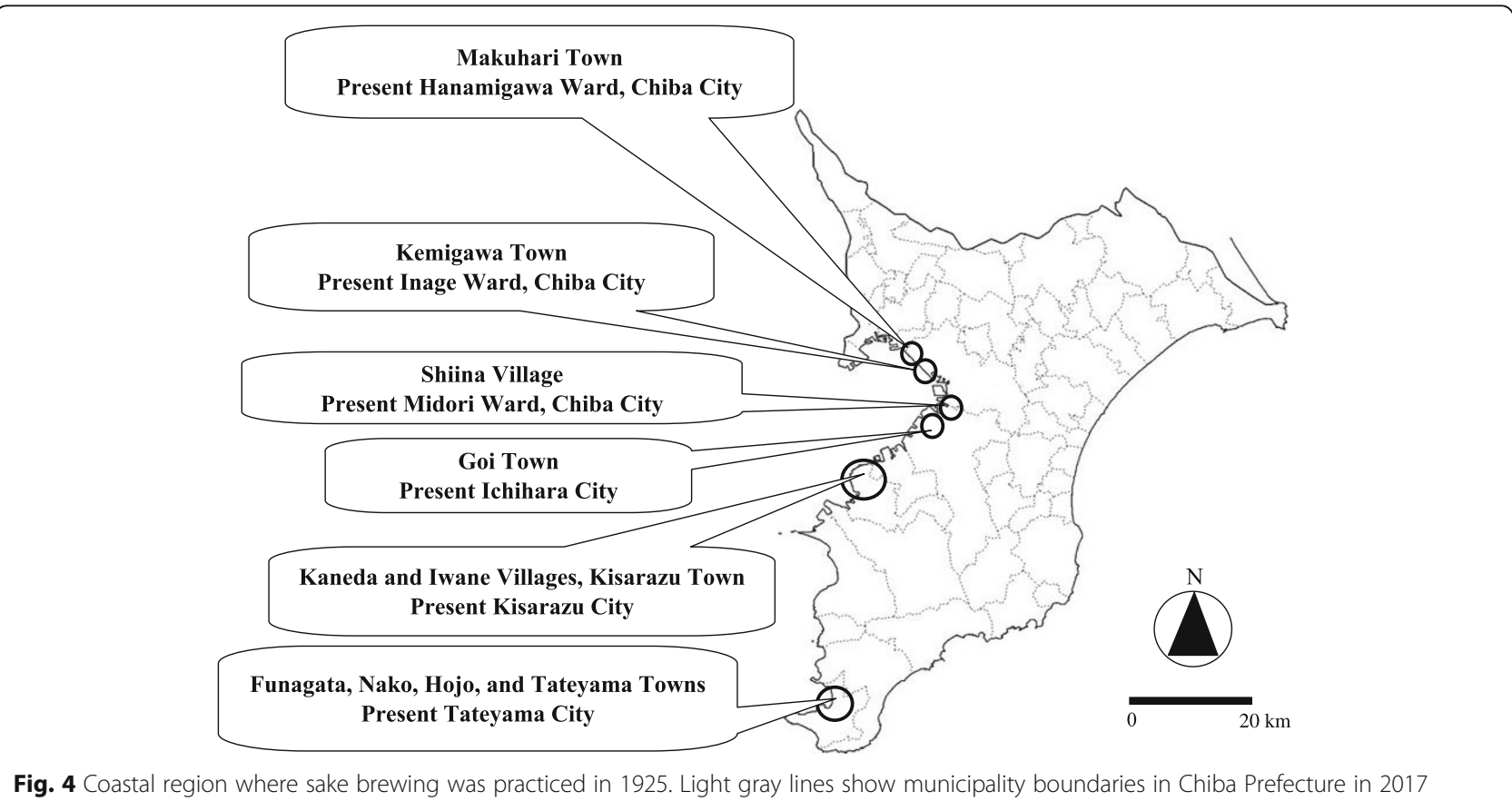

Fig. 4 Coastal region where sake brewing was practiced in 1925. Light gray lines show municipality boundaries in Chiba Prefecture in 2017 


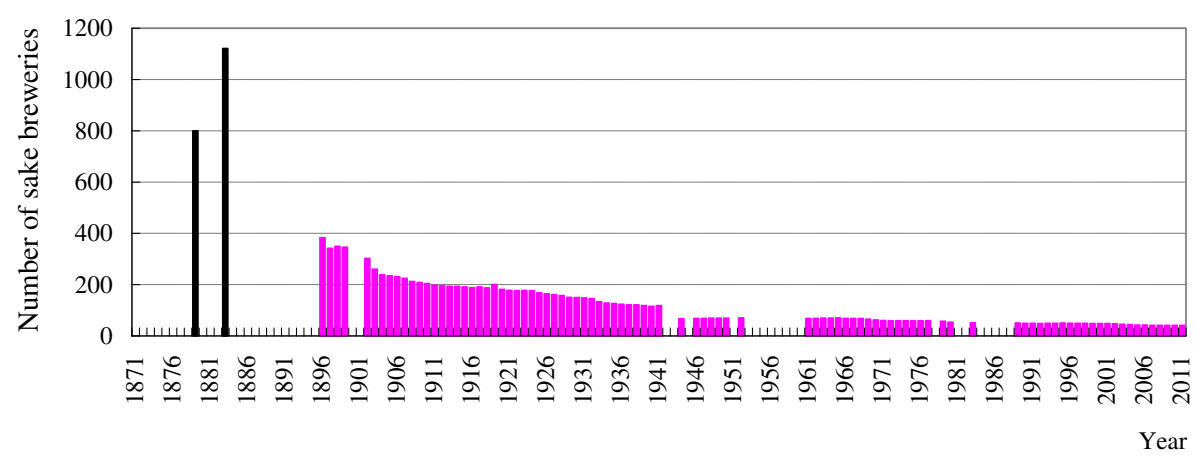

Fig. 5 Numbers of sake-brewery licensed in Chiba Prefecture (Chiba Prefecture 2012). Black bars indicate pre-home-brewing prohibition values

was operating in these regions in 1925 , including the altitude and distance from the sea. Sake breweries were frequently located on sandbanks, natural levees and sandbars, or in surface geology terms, on sand-rich sediments (Fig. 9). They were most often located within $1.0 \mathrm{~km}$ from the sea, at altitudes of $11.0 \mathrm{~m}$ or less. Even sake breweries located over $2.0 \mathrm{~km}$ from the sea were at relatively low altitudes of $5.0 \mathrm{~m}$ or less (Fig. 10).

\section{Groundwater quality}

The wells in Makuhari and Kemigawa Towns were 2.0-3.5 and 2.0-5.5 m deep, respectively. In Goi, Kisarazu, and Nako Towns, they were 3.6, 10 or less, and $3.0 \mathrm{~m}$ deep, respectively. The groundwater in all these locations was very hard (Chiba Prefecture 1966). Hojo Town had hard water at depths of $4.0 \mathrm{~m}$, Kaneda Village had medium hard water at depths of 5-10 m, and Tateyama Town had medium hard water at $4.0 \mathrm{~m}$ (Chiba Prefecture 1954 and 1963; Institute for Health in Chiba Prefecture 1983). We were unable to confirm the figures for Makuhari, Kemigawa, and Funagata Towns and Shiina and Iwane Villages (Table 2). Additionally, groundwater data for individual sake breweries were unavailable.

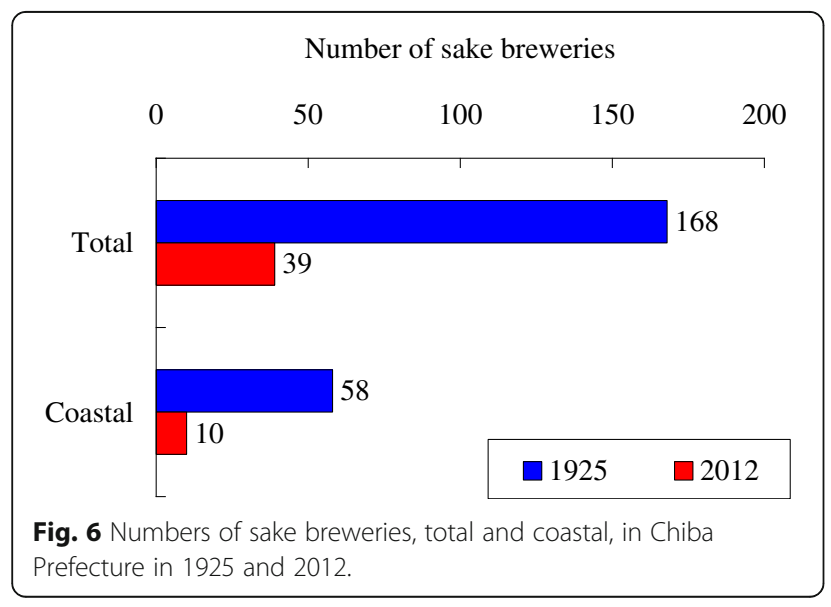

\section{Study site environment}

As noted above, the sake breweries operating in the coastal area along Tokyo Bay in 1925 were often situated at an altitude of approximately $10 \mathrm{~m}$, approximately $1.0 \mathrm{~km}$ from the sea (Figs. 8 and 9). The surface geology in their locations consisted of exceedingly soft sand-rich sediments, including sand, and the land is classified as sandbanks, natural levees, and sandbars (Table 1, Fig. 8). The topography inland from the coast in these regions is characterized by a coastal dune system in which sand and wetlands alternate, and there are hills and terraces (Fig. 7). Groundwater depths are 3-10 $\mathrm{m}$, and the water is variably hard, from medium hard to very hard (Table 2).

The groundwater under the sand dunes contains nutrients that originate in the remains of seaweed and animals deposited on the dunes and the salt spray carried by the wind. Nutrient concentrations are also high where sand-dune vegetation is abundant (Brown and Mclachlan 1990). In the marine sandy alluvial soil in Chiba Prefecture, potassium, phosphoric acid, calcium, and magnesium concentrations are high. The calcium concentration of the groundwater that flows through the aquifer that contains the shell layer has been influenced by the dissolution of splintered shells (Kaneko 1994; Kaneko et al. 1994). These nutrients actively promote the proliferation of Aspergillus oryzae and yeast, which are the predominant microorganisms used in sake brewing. Japanese sake that is brewed using hard water tends to be full-bodied, deep, and dry. Sake brewed using soft water tends to be mellower and slightly sweet (Inoue 2009). According to Kaneko et al. (2012, 2013), sake breweries that were on the sand dunes used groundwater depths of 5-10 m, which placed it deep within a freshwater layer in the sand dunes. Therefore, we believe that the Japanese sake brewed in the study area made use of this freshwater layer that was formed due to the coastal dune system. If such water was used to brew sake, it would have a dry, full-bodied taste.

The study cites all lie on alluvium. The alluvium forms an unpressurized aquifer based on the sand-rich 
a) Makuhari Town (Present Chiba City Hanamigawa Ward)
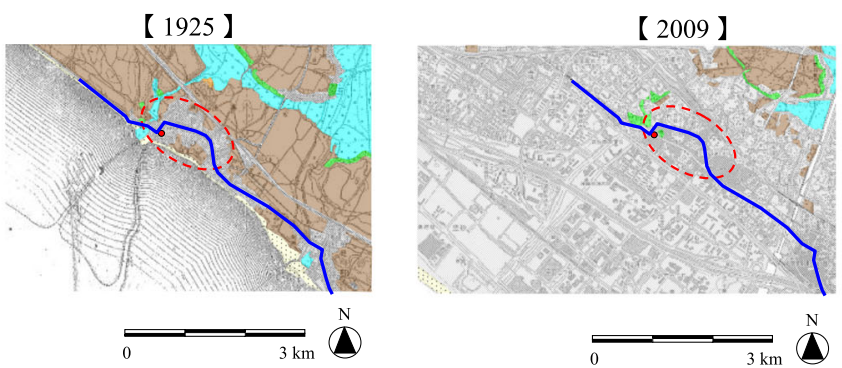

b) Kemigawa Town (Present Chiba City Inage Ward)

【1920】
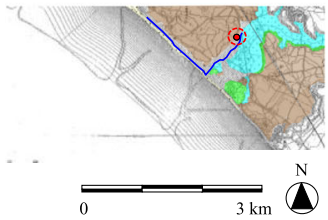

c) Shiina Village (Present Chiba City Midori Ward)

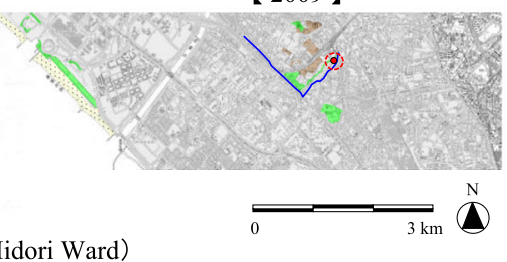

【2004】

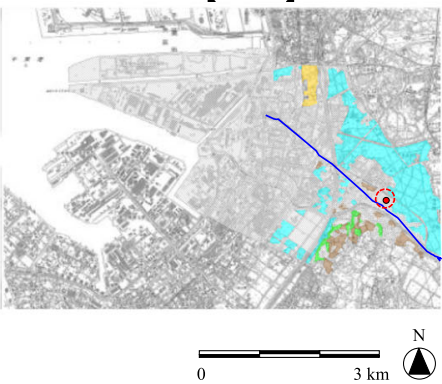

d) Goi Town (Present Ichihara City)

【1925】
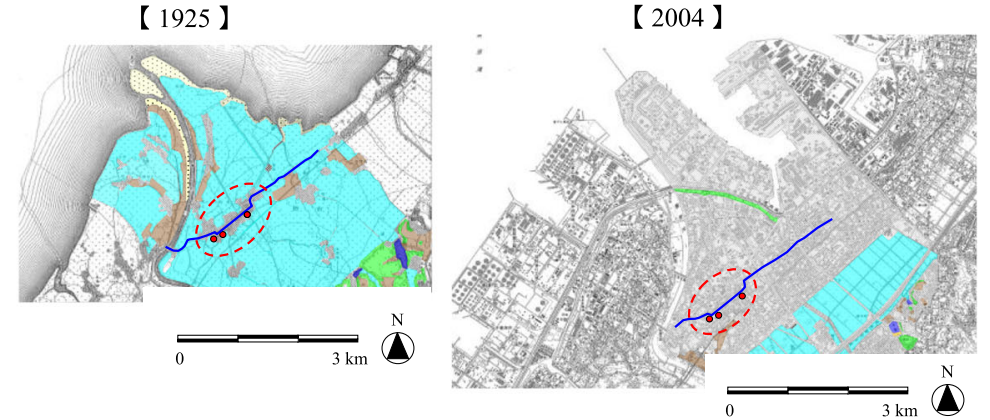

e) Hojo and Tateyama Towns (Present Tateyama City)
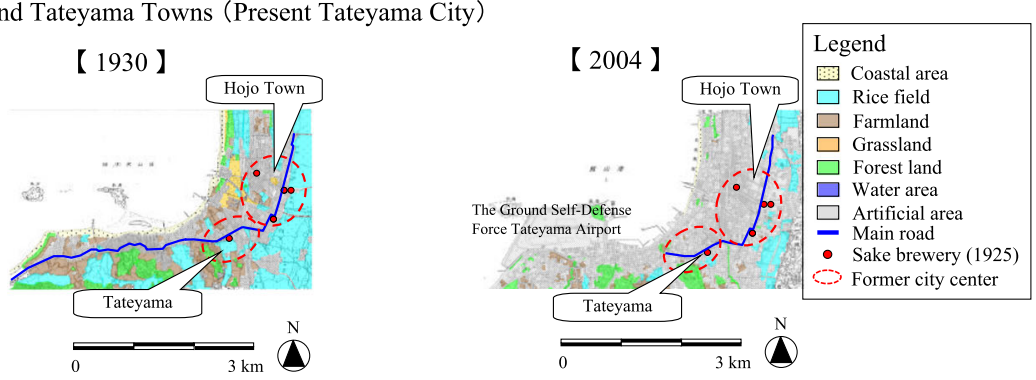

Fig. 7 Land use in the 1920s and 2000s. Base maps by the Geospatial Information Authority of Japan 
Table 1 Land classification, sub-surface geology, and soil type in study area

\begin{tabular}{|c|c|c|c|c|}
\hline \multicolumn{2}{|l|}{ Municipality } & \multirow[t]{2}{*}{ Land classification } & \multirow[t]{2}{*}{ Sub-surface geology } & \multirow[t]{2}{*}{ Soil } \\
\hline Taisho period & Present (2014) & & & \\
\hline Makuhari Town & $\begin{array}{l}\text { Hanamigawa ward } \\
\text { in Chiba City }\end{array}$ & Sand bank', natural levee & Sand-rich sediment ${ }^{a}$ & Unclassifiable \\
\hline Kemigawa Town & Inage ward in Chiba City & $\begin{array}{l}\text { Sand bank }{ }^{c} \text {, natural levee, } \\
\text { Covering dune }\end{array}$ & $\begin{array}{l}\text { Sand } 1^{\mathrm{b}} \\
\text { (exceedingly soft) }\end{array}$ & Unclassifiable \\
\hline Shiina Village & Midori ward in Chiba City & Sand bank', natural levee & Sand-rich sediment ${ }^{a}$ & Pale ando soils \\
\hline Goi Town & Ichihara City & Sand bank', natural levee & Sand-rich sediment ${ }^{a}$ & Rough particle gray soil \\
\hline Kaneda Village & Kisarazu City & Sand bar, sand bank, natural levee & Sand-rich sediment ${ }^{a}$ & $\begin{array}{l}\text { Rough particle gray soil, } \\
\text { Gray soil }\end{array}$ \\
\hline Iwane Village & & Sand bar, sand bank ${ }^{c}$, natural levee & Mud-rich sediments $^{d}$ & Gray soils \\
\hline Kisarazu Town & & $\begin{array}{l}\text { Sand bar, sand bank } \\
\text { natural levee, flood plains }\end{array}$ & $\begin{array}{l}\text { Sand } 1^{\mathrm{b}} \\
\text { (exceedingly soft) }\end{array}$ & $\begin{array}{l}\text { Rough particle gray soil, } \\
\text { Gray soil }\end{array}$ \\
\hline Funagata Town & Tateyama City & Sand bar (covered sand dune) & Sand-rich sediment ${ }^{\mathrm{a}}$ & Unclassifiable \\
\hline Nako Town & & Sand bar (covered sand dune) & Sand-rich sediment ${ }^{a}$ & Unclassifiable \\
\hline Hojo Town & & Sand bar & Sand-rich sediment ${ }^{a}$ & Unclassifiable \\
\hline Tateyama Town & & Sand bar & Sand-rich sediment ${ }^{a}$ & Unclassifiable \\
\hline
\end{tabular}

a Sand-rich sediments: composed of sand and sand banks in the coastal area and composed of fine- medium sand

${ }^{\mathrm{b}}$ Sand 1: consists of fine-to-medium grain sand, coarse sand, sandwiching a gravel clay. The thickness of the stratum is approximately $10-20 \mathrm{~m}$

'Sand bar-sand bank: beach ridge composed of sand forced near the coast by waves and coastal currents

${ }^{\mathrm{d}}$ Mud-rich sediments: distributed along the tributary valleys to cut the lowlands of the rivers and plateaus as well as the coastal lowland facing Tokyo Bay;

composed of silt and clay

sediment. However, the topography and geology are quite different, and the groundwater flow is different in the northern and southern parts of Chiba Prefecture. In the northern part, the aquifer tends to flow to an alluvial lowland on the coast of Tokyo Bay from the Shimousa Plateau, where the recharge area that provides water resources is rich in groundwater. However, in the Tateyama district in southern Chiba, there is little freshwater in the basement of the surrounding plateaus. However, in the alluvium along the coast and in the alluvial plain, where the study area is located, the unpressurized aquifer in the sand layer is used as for shallow wells (Institute for Health in Chiba Prefecture 1983).

Therefore, we conclude that because in 1925 development that would affect the groundwater supply had not yet occurred, the coastal dune system was in a relatively natural condition. Thus, water suitable for brewing could be taken from the groundwater of the coastal sand dunes along Tokyo Bay (Chiba Prefecture side), and sake brewing was feasible.

\section{Factors leading to sake brewery decline}

According to our survey results and other research, the following items caused the decline in sake brewing, compared to that practiced in the coastal area in 1925: (1) bankruptcies and reconstruction difficulties that followed the destructive 1923 Great Kanto earthquake (7 breweries); (2) the wartime Industrial Adjustment Act ( 6 breweries), which required the nation to adapt, integrate, or close non-military-related industrial facilities to support military-related industry during World War II (1939-1945); (3) the increased difficulty of sake brewing as a result of the large quantities of groundwater used by coastal industry during the 1960s and 1970s (1 brewery); and (4) altered transportation methods resulting from the development of distribution based on infrastructure improvements since the 1960s (e.g., changing from ships to railroad and road transport) (3 breweries), whereby (a) Japanese sake from other regions and imported alcoholic beverages such as beer, wine, and other alcohol could be obtained at cheaper prices, (b) changes in the availability of luxury goods occurred, and (c) it was no longer possible to sell sake brewed in the region.

\section{The Great Kanto earthquake disaster}

In Nako Town, there was a sake brewery until the Taisho era (1912-1926) (Nako District Union Neighborhood Association 2007). Other sake breweries known from records to exist in 1925 are as follows: 3 in Goi Town, 2 in Hojo Town, 1 in Tateyama Town, 1 in Funagata Town, 1 in Kaneda Village, 1 in Iwane Village, and 1 in Kisarazu Town (Chiba Prefecture Brewing Association 1885, Chiba Prefecture Brewing Association 1925). However, several sake breweries were not visible in a bird's-eye view of Chiba City (Matsui 1929). According to an interview with a descendant of a sake-brewing family that engaged in the brewing industry in Tateyama Town in 1925, the family 
a) Makuhari Town (Present Chiba City Hanamigawa Ward)

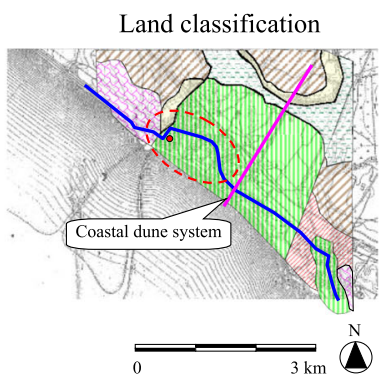

Surface geology

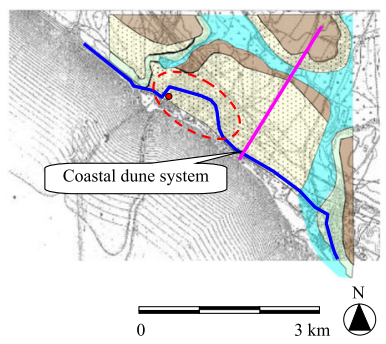

b) Kemigawa Town (Present Chiba City Inage Ward)
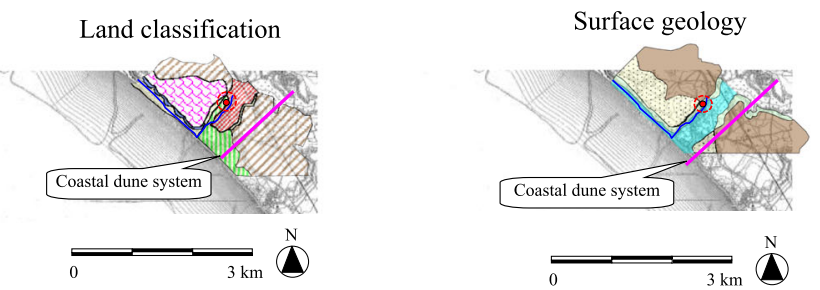

c) Shiina Village (Present Chiba City Midori Ward)
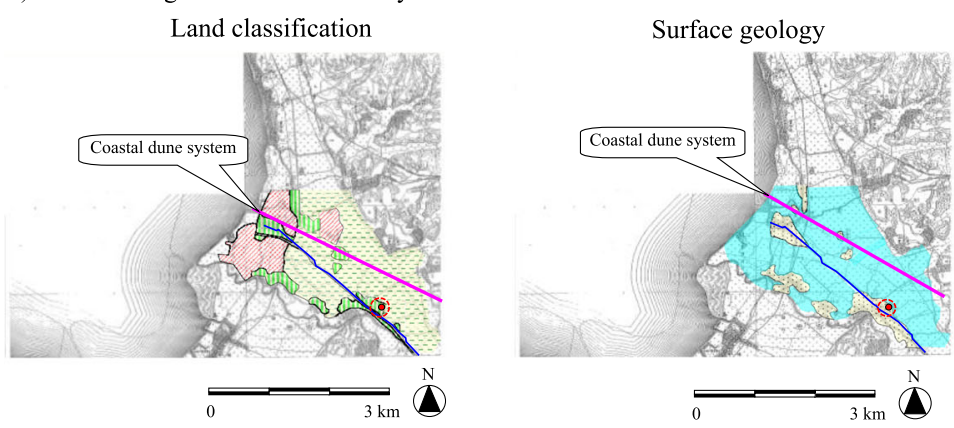

d) Goi Town (Present Ichihara City)
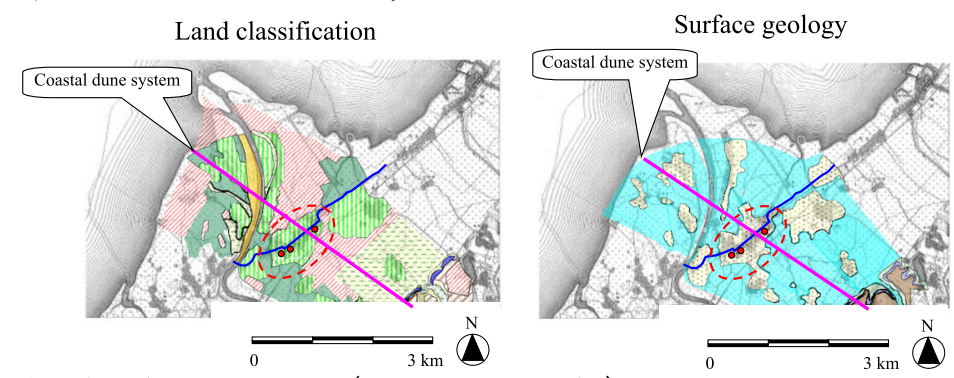

e) Hojo and Tateyama Towns (Present Tateyama City)
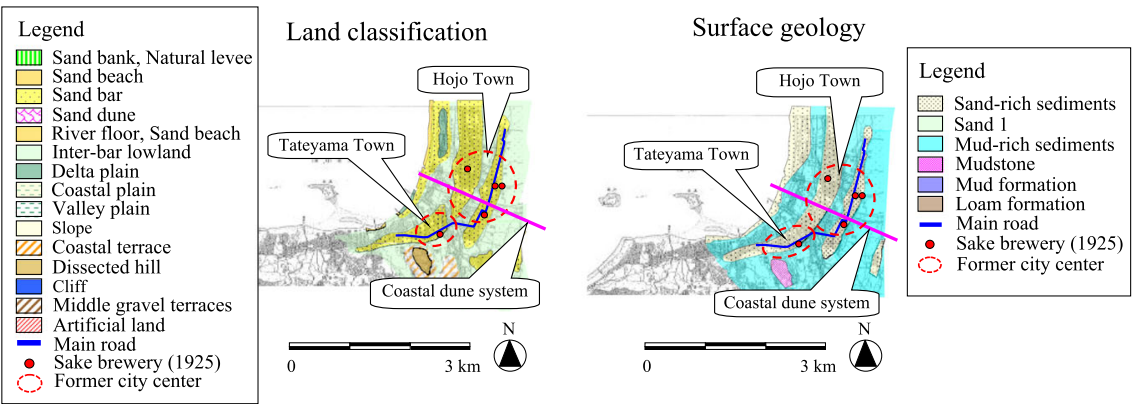

Fig. 8 Original land classification and surface geology in the coastal sake-brewing region in the 1920s. The base map is from the Geospatial Information Authority of Japan 


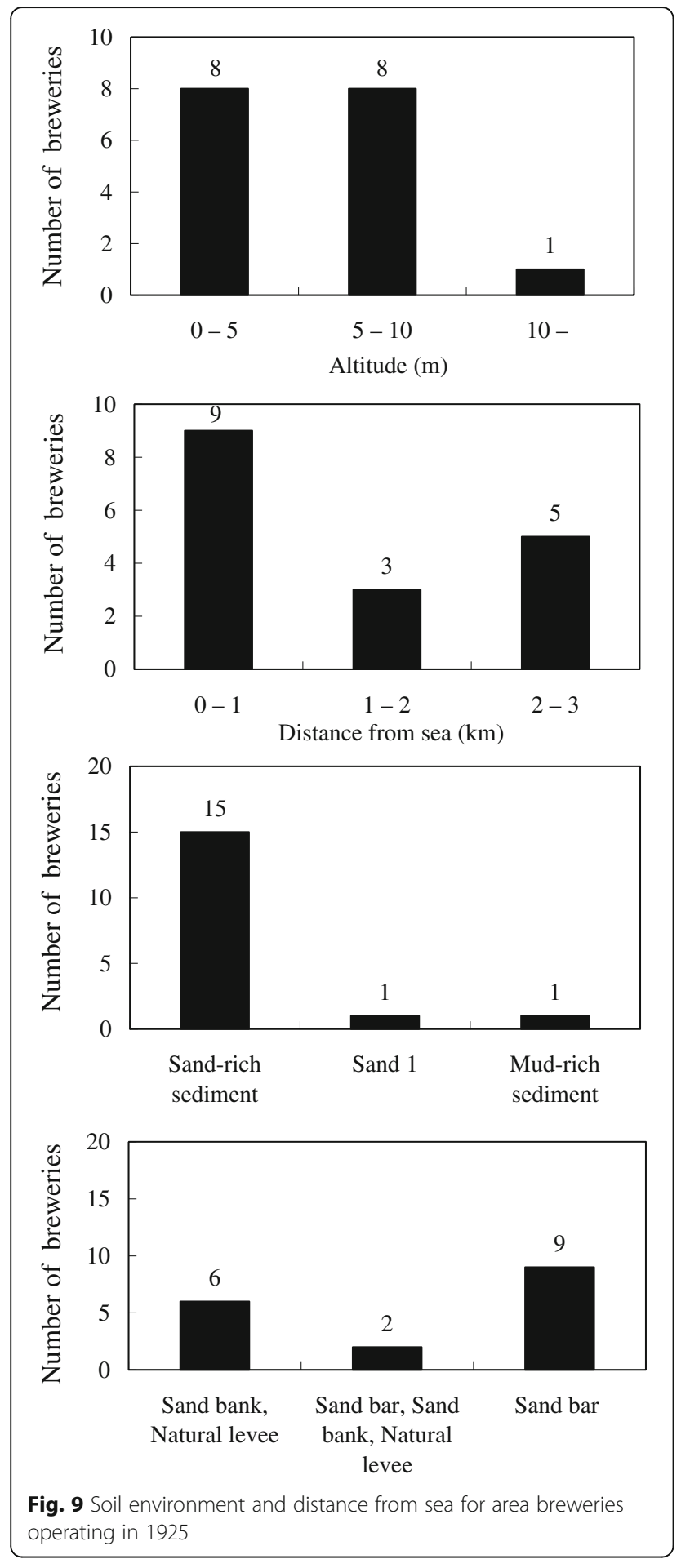

business ceased operation after the brewery building was destroyed by the 1923 Great Kanto earthquake. In addition, according to earthquake disaster records, Tateyama, Hojo, Nako, and Funagata Towns were destroyed by the earthquake, where $97-98 \%$ of the buildings were gutted by fire, and the brewing industry was devastated (Awa Country Office in Chiba

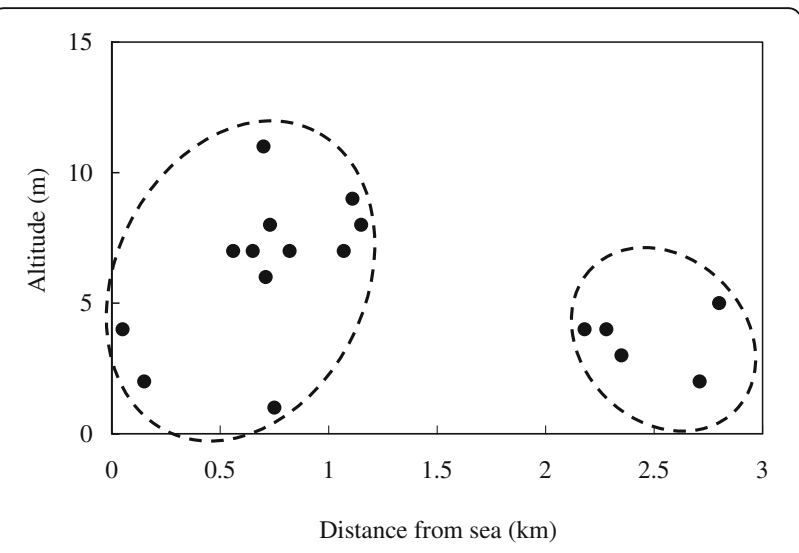

Fig. 10 Relationship between altitude and distance from sea. Data include all sake breweries operating in the study region in 1925

Prefecture 1925). We surmise that for small-scale sake breweries, reconstruction was financially difficult.

\section{Industrial adjustment in wartime}

Sake brewery closings because of the wartime industrial adjustment occurred in Goi Town and Iwane, Kaneda, and Shiina Villages in 1939-40. Although a sake brewery in Makuhari Town was depicted in a bird's-eye view of Makuhari Town from 1929 (Matsui 1929), the brewery was not included in the Chiba Prefecture brewery list of 1962 (Chiba Prefecture Brewing Association 1962). Therefore, it is likely that this brewery closed because of the wartime industrial adjustment.

\section{Coastal industrial development}

Reclamation was performed in the coastal zone of Tokyo Bay in Chiba Prefecture, from 1955 to 1975 to create land for the Keiyo coastal industrial zone (Chiba Enterprise Department Coastal Division 1976). In the Goi and Ichihara districts, development occurred from 1957 to 1963 (Chiba Prefecture Development Department 1961a). Because the quantity of groundwater pumped for industrial uses in the coastal area increased rapidly, the groundwater level decreased. This practice influenced private wells, and ground subsidence occurred (Chiba Prefecture Development Department 1961b). According to an interview with a descendant of a sakebrewing family from Shiina Village (present-day Midori Ward), although the vicinity of the sake brewery was rich in spring water (with an artesian spring water height of up to $20-30 \mathrm{~cm}$ throughout the area before coastal industrial development occurred), after the coastal industrial zones were created, artesian spring water was no longer seen. In addition, according to interviews with individuals who were engaged in the brewing industry until 1969 in Goi Town, after the reclamation of the coastal area for industrialization, the brewing industry 
Table 2 Study sites' water quality

\begin{tabular}{|c|c|c|c|c|c|c|c|}
\hline \multicolumn{2}{|l|}{ Municipality } & \multicolumn{6}{|c|}{ Water quality characteristics } \\
\hline \multirow{2}{*}{$\begin{array}{l}\text { Taisho period } \\
\text { Makuhari Town }\end{array}$} & \multirow{2}{*}{$\begin{array}{l}\text { Present (2014) } \\
\text { Hanamigawa Ward in Chiba City }\end{array}$} & \multicolumn{2}{|c|}{ Well depth (m) } & \multirow{2}{*}{$\begin{array}{l}\text { Total hardness (ppm) } \\
\text { - }\end{array}$} & \multirow{2}{*}{$\begin{array}{l}\text { Mg (ppm) } \\
-\end{array}$} & \multirow{2}{*}{$\begin{array}{l}\text { Ca (ppm) } \\
-\end{array}$} & \multirow{2}{*}{$\frac{\text { Water sampling period }}{\text { Before } 1954^{a}}$} \\
\hline & & Shallow well & $2.0-3.5$ & & & & \\
\hline Kemigawa Town & Inage Ward in Chiba City & Shallow well & $2.0-5.5$ & - & - & - & Before $1954^{a}$ \\
\hline Shiina Village & Midori Ward in Chiba City & - & - & - & - & - & - \\
\hline Goi Town & Ichihara City & Shallow well & 3.6 & 230.3 & - & 92.0 & Before $1966^{b}$ \\
\hline Kaneda Village & Kisarazu City & Shallow well & $5-10$ & 75.0 & 7.0 & 18.4 & May $1953^{c}$ \\
\hline Iwane Village & & - & - & - & - & - & - \\
\hline Kisarazu Town & & Shallow well & $<10$ & 267.8 & 12.4 & 87.0 & May $1953^{c}$ \\
\hline Funagata Town & Tateyama City & - & - & - & - & - & - \\
\hline Nako Town & & Shallow well & 3.0 & 196.0 & 15.8 & 52.0 & September $1953^{c}$ \\
\hline Hojo Town & & Shallow well & 4.0 & 156.0 & 18.9 & 32.4 & September $1965^{\circ}$ \\
\hline Tateyama Town & & Shallow well & 5.0 & 106.8 & 14.7 & 19.2 & September $1963^{d}$ \\
\hline
\end{tabular}

${ }^{a}$ Chiba Prefecture (1954) Groundwater investigation report in the suburbs of Chiba City

${ }^{b}$ Chiba Prefecture (1966) Groundwater of Chiba Prefecture

Institute for health in Chiba Prefecture(1983) Ground water quality document collection in Chiba Prefecture

${ }^{d}$ Chiba Prefecture(1963) Annual reports of Industrial Res. Inst. of Chiba Prefecture

ceased operation because the well water had become polluted. The pollution was confirmed by color tone, organic matter at concentrations greater than $1000 \mathrm{ppm}$, and the detection of ammonia. Thus, high-quality groundwater was no longer available (Chiba Prefecture 1963). Although spring water occurred in many artesian wells in Chiba Prefecture, the pumping increased because of continuing urbanization and the development of industry and agriculture. Therefore, the groundwater level decreased, as did the number of artesian wells. In particular, artesian wells distributed in the center of Goi Town, dug using the Kazusa-bori technique (a representative construction method in which wells are dug using bamboo), subsided for several years and then disappeared after the pumping of industrial water for the Keiyo industrial complex on Tokyo Bay commenced (Chiba Prefecture 2002). Therefore, we can conclude that the sake breweries located near the developed area could no longer be assured of an adequate supply of water because of the large quantity of groundwater used by industry and because of industrial pollution of the groundwater. Thus, the breweries in the district could no longer brew sake.

Increased availability of luxury goods due to distribution system development

Viewing the history of sake in Chiba Prefecture and the surrounding areas, the Japanese sake brewing industry of the Kanto area, which is located in the eastern part of Japan, was done on a small scale, was relatively undeveloped, and was of inferior quality compared to that of the Kansai area located in midwest Japan. The Kansai sake industry has been continuously producing for the Edo (now Tokyo) market since the beginning of the seventeenth century. Therefore, Japanese sake made in the Kanto area was deemed to be inferior local sake and was neglected by both Samurai and commoners in Edo. The Edo feudal government aimed to improve the quality and increase the volume produced by representative sake breweries and tried to restrict the volume of Japanese sake in Kansai. As a result, the Edo feudal government could not restrict the imported volume of sake from the Kansai area to Edo, and Japanese sake from Kansai was more popular than that from Kanto. However, this policy later led to improvements in the brewing technology of Kanto (Yoshida 1997a). The volume of kudari-zake shipped to Edo in 1856 was 72 million liters, whereas there were only 7.2 million liters of jimawari-zake, sake made in the Kanto area. Because of this, residents in Edo drank kudari-zake overwhelmingly. Sawara Village (now Katori City in Chiba Prefecture) produced jimawari-zake that was shipped to Edo. In 1789, it shipped 37,800 l of sake to Edo in 1789 (Yoshida 1997b). Moreover, although sake breweries in the various parts of Chiba Prefecture shipped to neighboring areas, there was no connection with Edo (Yoshida 1997a; 1997b; Takahashi, 2012). In the fishing villages of Chiba Prefecture in the Edo period, there was one sake brewery per village. People engaged in the heavy labor of fishing exerted a large demand for sake, so sake brewing developed (Chiba Prefecture 2009). We expect that people in Chiba Prefecture drank local sake during the Edo period.

According to an interview with a descendant of a sake-brewing family from Hojo Town, this region had a custom of drinking sake from other regions. Therefore, we researched the shares of alcohol consumption in 
Chiba Prefecture. The consumption of Japanese sake has indeed decreased, whereas beer consumption increased until 1994, and consumption of other alcoholic beverages have increased since the 2000s (Fig. 11). The reason for this change is that other alcoholic beverages are cheaper and easier to drink than beer. Moreover, consumption of Japanese sake produced in Chiba Prefecture has decreased, moving toward consumption of sake produced outside of Chiba Prefecture, as PR advertising has become more effective and transport has undergone remarkable improvement. Japanese sake was originally transported by land and sea before World War II, and demand within the prefecture was satisfied in those days. Nearly two thirds of the Japanese sake consumed in Chiba Prefecture came from outside the prefecture (Chiba Prefecture Brewing Association 1970a, b). The production of local sake in Chiba Prefecture decreased from $30.6 \%$ in 1979 to $25.4 \%$ in 2015 , down to about one fourth of the prefecture's consumption (Fig. 12). Thus, even 40 years ago, people in Chiba preferred drinking sake brewed in other prefectures in Japan over local sake (National Tax Agency HP: http://www.nta.go.jp/kohyo/tokei/kokuzeicho/jikeiretsu/01.htm).

It is clear that recent developments in the distribution system, thanks to improved highway infrastructure, have increased the availability of Japanese sake brewed in other regions and imported alcoholic beverages, such as beer and wine. The increased availability of such luxury goods had a significant detrimental impact on Chiba's sake breweries. There were three sake breweries in Tateyama Town in a list compiled by the Chiba Prefecture Brewing Association (1977), and according to information from our survey, the brewing industry operated until the 1980s or 1990s. All of these sake breweries have gone out of business because of the combination of reasons presented above.

\section{Conclusions}

In this study, we investigated potential environmental factors (e.g., landscape, soil, and ground water) and societal factors that were favorable for sake brewing in the coastal area in the 1920s. We clarified how sake brewing in these areas benefited from their proximity to the coast (the ecosystem service).

The breweries operating in the coastal area along Tokyo Bay in 1925 were often located below $10 \mathrm{~m}$ in altitude and within $1 \mathrm{~km}$ of the sea (Fig. 10). The surface geology consisted of exceedingly soft sand-rich sediments, including sand. The groundwater, ranging from medium hard to very hard, lay 3-10 m below the surface (Tables 2 and 3). The topography from the coast to the plateau in these regions is a coastal dune system in which sand and wetlands alternate, rising to a plateau (Fig. 8).

The groundwater under the sand dunes contains nutrients that originate in the remains of seaweed and animals deposited on the dunes and the salt spray carried by the wind. Nutrient concentrations are also high where
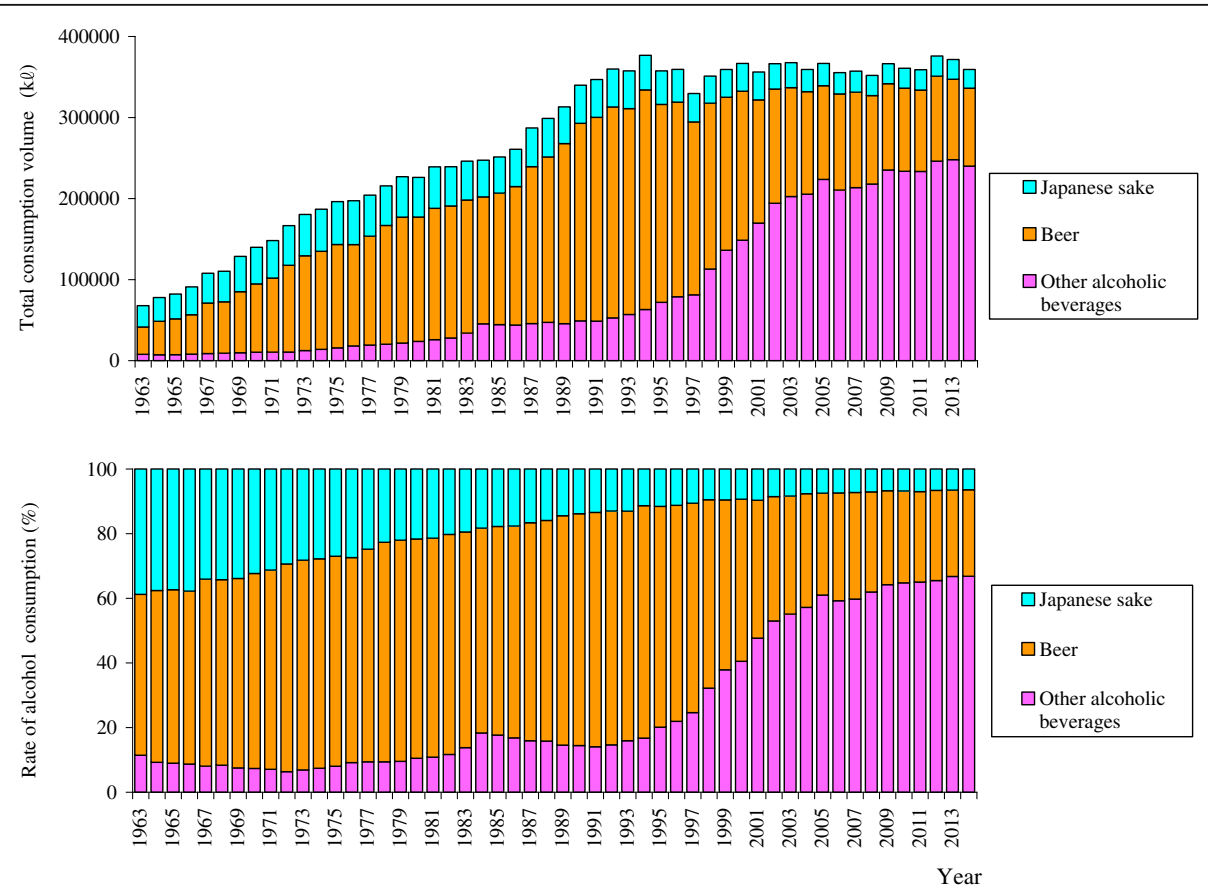

Fig. 11 Total consumption volumes and proportions of alcohol consumption in Chiba Prefecture (National Tax Agency HP https://www.nta.go.jp/kohyo/tokei/kokuzeicho/jikeiretsu/01.htm) 

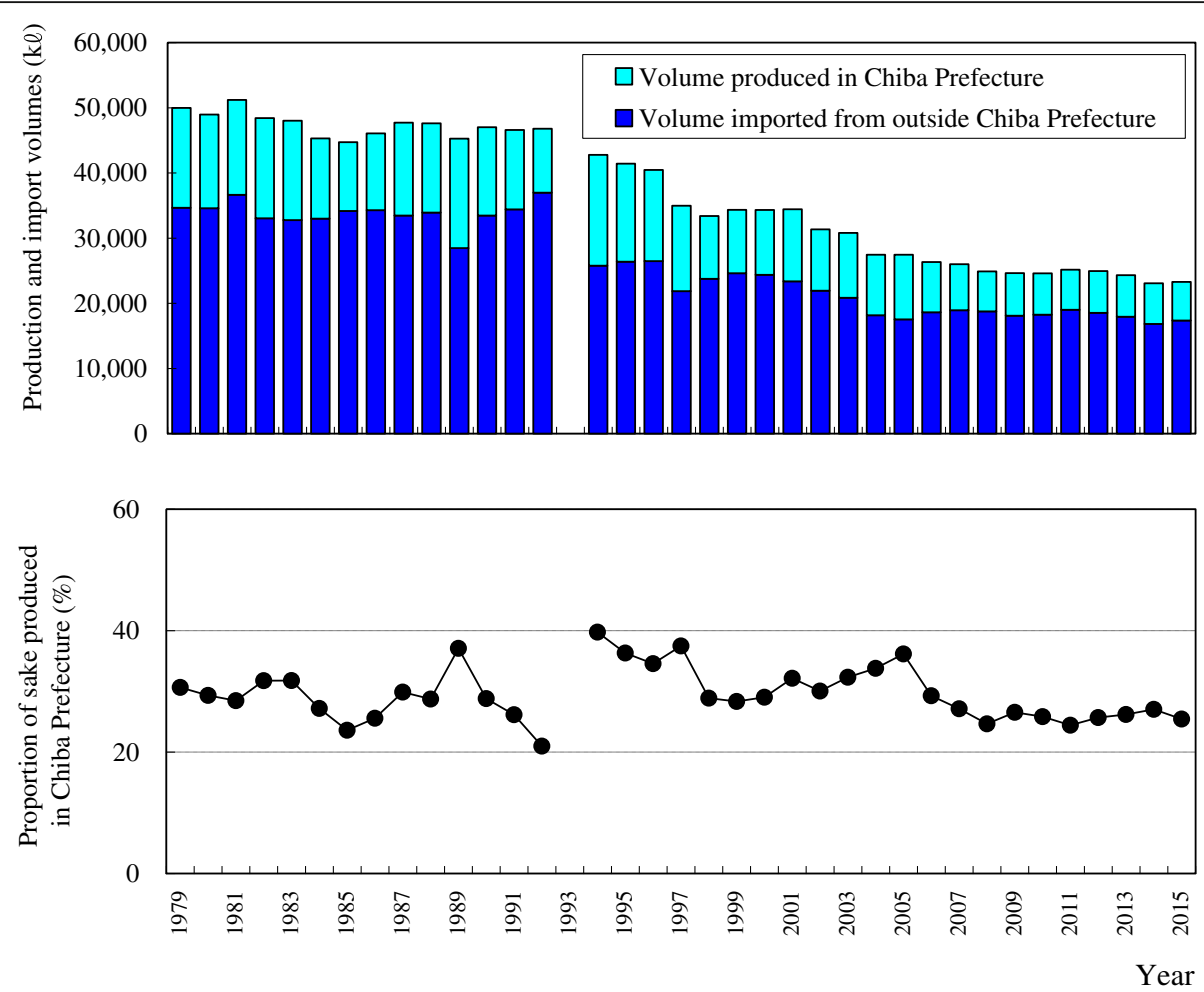

Fig. 12 Sake volume produced in Chiba Prefecture and imported from outside the prefecture. Source: (National Tax Agency HP https://www.nta.go.jp/kohyo/tokei/kokuzeicho/jikeiretsu/01.htm) Data for 1993 was unavailable

sand-dune vegetation is abundant (Brown and Mclachlan 1990). The study sites all lay on alluvium, which forms an unpressurized aquifer in the sand-rich sediment. The groundwater in the northern part of the prefecture tends to flow to an alluvial lowland on the coast of Tokyo Bay from the Shimousa Plateau, which has an abundance of groundwater (Fig. 2). However, in the Tateyama district in the south, there is little freshwater in the basements of the surrounding plateaus. The unpressurized aquifer in the sand layer is used for shallow wells (Institute for Health in Chiba Prefecture 1983).

In the sandy marine alluvial soil in Chiba Prefecture, potassium, phosphoric acid, calcium, and magnesium concentrations are high. The calcium concentration of the groundwater in the aquifer containing the shell layer has been raised by the dissolution of splintered shells (Kaneko 1994; Kaneko et al. 1994).

Table 3 Water hardness classification

\begin{tabular}{ll}
\hline Hardness classification & USA hardness $(\mathrm{ppm})$ \\
\hline Soft water & $0-60$ less than ${ }^{\mathrm{a}}$ \\
Medium hard water & $60-120$ less than ${ }^{\mathrm{a}}$ \\
Hard water & $120-180$ less than \\
Very hard water & 180 or more $^{\mathrm{a}}$ \\
\hline
\end{tabular}

${ }^{\mathrm{a} W o r l d}$ Health Organization (2011)
Most of the sake brewery wells on the coast in Chiba Prefecture were approximately 5-10 m underground, providing a mineral-rich, hard water, high in calcium and magnesium (Kaneko et al. 2012, 2013). Much of the sake brewed in the study area used water from a freshwater layer formed by the coastal dune system.

We also clarified the following as factors that caused the decline of sake brewing as practiced in the coastal area in 1925: (1) bankruptcies and reconstruction difficulties that followed the destructive 1923 Great Kanto earthquake; (2) the wartime Industrial Adjustment Act, under which the nation was required to adapt, integrate, or close non-military-related industrial facilities to support military-related industries during World War II (1939-1945); (3) increased difficulty of sake brewing due to large quantities of groundwater being used by coastal industries during the 1960s and 1970s; and (4) altered transportation and distribution systems resulting from infrastructure improvements (e.g., changing from ship transport to railroads and roads), whereby Japanese sake from other regions and imported alcoholic beverages (e.g., beer and wine) could be obtained at cheaper prices. This brought on changes in the availability of luxury goods, and it was no longer possible to sell locally brewed sake. 
Originally, we hypothesized that the fate of Chiba's sake breweries was linked to the natural endowments of the local area. However, the situation is more complex than that, and many sake breweries went out of business because of changes in social circumstances.

\section{Acknowledgements}

We wish to express our sincere gratitude to the individuals engaged in sake brewing in Chiba Prefecture, Japan, Chiba Prefectural Library, and Chiba Prefectural Archives that provided Japanese sake information for their support of this research.

\section{Funding}

Not applicable.

\section{Authors' contributions}

Both authors carried out the ecosystem services studies, participated in the sake breweries investigation and drafted the manuscript. KK participated in the design of the study and performed the statistical analysis. HM participated in its design and coodination. Both authors read and approved in the final manuscript.

\section{Competing interests}

The authors declare that they have no competing interests.

\section{Publisher's Note}

Springer Nature remains neutral with regard to jurisdictional claims in published maps and institutional affiliations.

\section{Author details}

'Hokuso Creature Association, 4-20-5 Tabata, Kita-Ward, Tokyo 114-0014, Japan. ${ }^{2}$ Research Faculty of Agriculture, Hokkaido University, Sapporo, Japan.

Received: 9 August 2016 Accepted: 8 September 2017

Published online: 02 October 2017

\section{References}

Awa Country Office in Chiba Prefecture (1925) Awa - Chihou no Zishin Saigai. Rinsen Book Co., Kyoto

Brown AC, Mclachlan A (1990) Ecology of Sandy shores. Elsevier, Amsterdam Chiba Prefecture Brewing Association (1970a) Sake natural features record Chiba. J Brew Soc Japan 65(9):775-778

Chiba Enterprise Department Coastal Division (1976) Keiyo coastal region development catalog. Chiba Prefecture: pp 9-19

Chiba Prefecture (1954) Groundwater investigation report on the suburbs of Chiba City, Chiba Prefecture, Chiba

Chiba Prefecture (1963) Annual report of industrial research. Institute of Chiba Prefecture, Chiba

Chiba Prefecture (1966) The ground water of Chiba Prefecture. Chiba Prefecture, Chiba

Chiba Prefecture (2001) Natural Magazine in Chiba Prefecture. Mainland 2, Chiba Prefecture, Chiba

Chiba Prefecture (2002) Inland water. In: Chiba Historical Materials Study Foundation (ed), Chiba Prefectural Nature, vol 2. Chiba Prefecture, Chiba

Chiba Prefecture (2009) History of Chiba. History Edition, Early Modern I, Chiba Prefecture Data Research Foundation, Chiba

Chiba Prefecture (2012) 2011 Chiba Prefecture Statistical Yearbook. Chiba Prefecture, Chiba

Chiba Prefecture Brewing Association (1885) Chiba-ken shuzo-kumiai kumiaikaihou. Chiba Prefecture Brewing Association, Chiba

Chiba Prefecture Brewing Association (1925) Chiba-ken shuzo-kumiai kumiaiinmeibo. Chiba Prefecture Brewing Association, Chiba

Chiba Prefecture Brewing Association (1962) Chiba-ken shuzo-kumiai kumiaiinmeibo. Chiba Prefecture Brewing Association, Chiba

Chiba Prefecture Brewing Association (1970b) Chiba-ken shuzo-kumiai kumiaiinmeibo. Chiba Prefecture Brewing Association, Chiba

Chiba Prefecture Brewing Association (1977) Chiba-ken shuzo-kumiai kumiaiinmeibo. Chiba Prefecture Brewing Association, Chiba
Chiba Prefecture Development Department (1961a) History of Keiyo coastal industrial zone. Part 3 industrial water. Chiba, Chiba Prefecture: pp 12-17

Chiba Prefecture Development Department (1961b) Keiyo coastal industrial zone: realities of industrialization and changes in the local community. Chiba, Chiba Prefecture: pp $71-75$

Food and Beverage Specialist Organization NPO (2009) Nihonshu no Motoi: to you who aim to be professional sommeliers of Japanese sake. Lecture Text. Sake Service Institute, Tokyo

Institute for Health in Chiba Prefecture (1983) Document collection of ground water quality in Chiba Prefecture. Chiba Prefecture, Chiba

Inoue M (2009) Promotion of empirical study of sediment transport system problems from mountainous districts to river and sea areas. Science and Technology Trend May: 19-32

Kaneko F (1994) Groundwater quality in Chiba prefecture characterized with solution equilibria and mineral stability diagrams. Jpn I Soil Sci Plant Nutr 65:175-183

Kaneko F, Imaizumi M, Hamada H, Komae T (1994) Aquifer coefficient and condition of groundwater flow of the marine sandy alluvial plain in Chiba prefecture. Jpn J Soil Sci Plant Nutr 65:297-303

Kaneko K, Oshida K, Matsushima H (2012) Ecosystem services on coastal sand beaches, their significance as provisioning, regulating, and cultural services. Jpn J Assoc Landscape Ecol 17(1):19-24

Kaneko K, Oshida K, Matsushima H (2013) Ecosystem services of coastal sand dunes seen from the aspect of sake breweries in Chiba prefecture, Japan: a comparison of coastal and inland areas. Open J Ecol 3(1):48-52

Matsui T (1929) Chiba Kenshigai Choukaizu

Ministry of Land, Infrastructure, Transport and Tourism, National Land Information. 1:50000 state fundamental land classification survey (Chiba Prefecture HP). http://nrb-www.mlit.go.jp/kokjo/inspect/landclassification/ land/5-1/1212.html. Accessed. 22 Feb 2000

Nako District Union Neighborhood Association (2007) Nako District History. Chiba Prefecture, Chiba

National Tax Agency HP (http://www.nta.go.jp/kohyo/tokei/kokuzeicho/jikeiretsu/ 01.htm)

Suzuki K (1997) Chiba no Sake Monogatari: Sake-Zukuri - Kokoro, Fudo, and Rekishi. Chiba Brewing Association, Chiba

Takahashi N (2012) Sake of Boso in the Edo period: from manufacturing to sales and consumption. Prefectural history course of Chiba Prefectural archives

World Health Organization (2011) Hardness in Drinking-Water. Background document for development of WHO Guidelines for Drinking-Water Quality:1-11

Yoshida H (1997a) Sake of Edo - Technology, Economics, Culture -. Asahi Sensho 569 , Tokyo

Yoshida Y (1997b) Local sake production and commercialization in the Edo period (2): as a center local merchant area in Edo. Jpn J Dietary Sci Res 18(5):11-20

\section{Submit your manuscript to a SpringerOpen ${ }^{\circ}$ journal and benefit from:}

- Convenient online submission

- Rigorous peer review

- Open access: articles freely available online

- High visibility within the field

- Retaining the copyright to your article

Submit your next manuscript at $\boldsymbol{\nabla}$ springeropen.com 